\title{
Understanding Issues Associated with Tracking Students in Mathematics Education
}

\author{
Cacey L. Wells \\ University of Oklahoma, USA
}

Academic tracking, particularly in subjects like mathematics, has existed in the United States' education system for decades. A problem with tracking is that, in many cases, students are sorted based on external factors beyond their control, rather than their abilities. This article expounds upon theory supporting these claims, providing support through literature that suggests tracking is rooted in capitalist exploitations and settler colonialism. In deconstructing tracking in schools, connections are made that illustrate how tracking creates cultures of academic apartheid, providing advantages for some and disadvantages for others. To conclude, possibilities are proposed to begin rethinking mathematical curriculum in order to disrupt tracking in education. These possibilities include creating spaces in schools for democratic learning environments to thrive, while calling for curriculum to be structured around students' interests. Furthermore, ideas like incorporating multiple perspectives in mathematics curricula through rethinking the labels associated with mathematics courses, teaching mathematics through the context of history, and teaching mathematics for social justice, are introduced. Each proposal serves as a potential alternative to traditional, hierarchical mathematics curriculum.

Keywords: tracking, mathematics curriculum, settler colonialism, academic apartheid.

Sorting is one way in which we try to make sense of the world around us. Although the world is becoming increasingly more complex, binary thinking has become arborescent, rooted in our consciousness (Capra, 1996). Taxonomic binaries often manifest themselves in education through sorting students into mathematics courses based on ability. Many theorists refer to systematically sorting students as tracking (Barquet, 1992; Battey, 2013; Martin, 2009; Moses \& Cobb, 2001; Oakes, 2005; Wheelock, 1992). In tracking students, we often provide labels such as advanced, regular, honors, or vocational to describe them. The varied connotations associated with each category often become defined through binary oppositions.

Tracking is often introduced in mathematics curriculum as a positive way for students to invest in their learning as they prepare to enter higher 
education or the workforce (Oakes \& Guiton, 1995). In this view of tracking, students are sorted based on ability and prior achievements. The author contends, though, that the manner in which students are sorted into mathematics courses is often based on external factors, such as race and/or socioeconomic status, rather than ability and student choice. The results of tracking students in mathematics often include reproduction of social class and unequal access to resources (Battey, 2013; Oakes, 2005; Oakes \& Guiton, 1995). The aims of this article are to explore theoretical literature supporting these claims and to propose potential solutions for rethinking mathematics curricula. More specifically, this article seeks to answer the following questions: What is tracking? What are the effects of tracking on students in schools in the US? And, what might alternatives to tracking look like based on theory and literature?

\section{Theoretical Framework}

Tracking students is not a new concept in education. In fact, functional models of education, which include tracking systems, have been implemented in schools since the 1920s (Bobbitt, 1924; Oakes, 2005; Schiro, 2013). Sorting students to create more homogeneous classrooms is a very efficient way of organizing curricula in schools. In recent years, tracking students has become more popular, in part, due to demands on teachers and students to perform in an age of top-down, reform movements (Houser, Krutka, Province-Roberts, Pennington, \& Faili-Coerver, 2017; Schiro, 2013). The theoretical literature discussed below adds context to the roots of tracking culture as a manifestation of hierarchical power structures, which reinforce hegemonic practices in schools.

To conduct this review of literature, many different sources were incorporated, including: journals, books, reports, and dissertations. These sources were accessed through Eric, EbscoHost, ProQuest, Jstor, and Google Scholar. A number of synonyms and related phrases were used in my searches, including "tracking"; "tracking in mathematics"; "sorting students"; "educational tracking"; "benefits of tracking", "implications of tracking"; and "results of tracking." After searching, articles were synthesized into themes around the history of tracking in mathematics education, constructs of tracking, and adverse impacts of tracking.

\section{The Roots of Tracking}

A common belief is that, in order for society to progress, schools must produce students to fill specific needs in labor markets (Bobbitt, 1924; Schiro, 2013). Functional models of schooling are ways in which societies seek to produce students to fill needs for the betterment of humanity (Schiro, 2013). Mathematics education in the United States has seen increased demands to compete globally with other industrialized countries that are outperforming US 
students on achievement assessments. In order to compete in global markets, many policymakers have advocated for more efficient models of curriculum (Kilpatrick, 2014; Teitelbaum, 2014). As a result, practices like tracking have been implemented to more effectively sort students in an effort to help the US become more globally competitive (Oakes, 2005; Wheelock, 1992).

At first glance, desires for the US to compete globally may not be inherently wrong. Reform initiatives, such as Race to the Top, are enacted to potentially help achieve these lofty goals. As schools strive to produce competent students, capable of performing well on global stages, the systems put in place to achieve such goals oftentimes become corrupted (Oakes, 2005; Wheelock, 1992). As students are sorted into different tracks, some students are privileged, while others are not given the same opportunities for success (Battey, 2013). As increased demands to produce people to fill voids in more desirable markets, less desirable voids are created in societies that need to be filled by someone. This is one instance where tracking can be exploited in order to provide advantages for some, while disadvantaging others (Battey, 2013; Oakes, 2005; Oakes \& Guiton, 1995; Werblow, Urick, \& Duesbery, 2013).

The advantages and disadvantages students face in schools are often unintentionally taught. Anyon $(1979,1981)$ found that teachers often teach in ways that inadvertently reproduce social class. For instance, she found that language used in some working-class schools was consistent with factory-style, working class jobs which employed many families in the surrounding community. Technical language, coupled with curricula rooted in rote memory, served to reinforce social class stratification. Additionally, students in working class schools were not given the same opportunities to use higher-order thinking skills as their more affluent counterparts (Anyon, 1979, 1981).

As capitalist agendas manifest themselves in schools, students are perpetually churned out of the education system to fill needs in society. Whether it is reproducing lower-socioeconomic classes to fill working class jobs or grooming new elites to manage others, schools often cater to student potentialities based on societal norms (Anyon, 1979, 1981). It then makes sense that schools often serve to promote "social cleavages" and cater to "group-based identities to advance [political elite's] agendas" (Powell \& Menendian, 2016, p. 22). Within the roots of capitalist America is an oft unspoken code that people of color have less potential than their white counterparts. This is, in part, due to capitalist exploitations rooted in colonialism.

\section{Settler Colonialism and Othering}

As a country, the United States was born out of a colonized people, oppressed under British rule (Rippa, 1984). The relationship between an oppressed group and their oppressors is founded on the nature of control. Freire (2000) was wary scenarios where the oppressed, if given an opportunity to unseat those in positions of power, would assume the role of oppressor rather than transcending the system entirely. In the United States, this was, in fact, the 
case. The colonized had become the colonizers (Hoxie, 2008). As the quest for territory became a priority in the US, a specific type of colonization, which systematically oppresses people of color, became more widespread. This type of colonization is commonly referred to as settler colonialism (Hixson, 2013; Hoxie, 2008; Patel, 2016; Wolf, 1999).

In order for settler communities to flourish, "constructions, hierarchies, and inclusions and exclusions pertaining to race, class, gender, religion, and nation" must exist (Hixson, 2013, p. 9). Through conquest, oppressed people oftentimes become homogenized others. Social constructions built on mechanisms of control cause separation between people, resulting in class distinctions, racism, sexism, and prejudice. "Once established, group-based identities may seem so fundamental that we ordinarily perceive them as "natural"" (Powell \& Menendian, 2016, p. 24). Othering allows those in power to see their subordinates as being less than human, and thus, easier to conquer and control (Ellsworth, 1992; Patel, 2016; Said, 1978; Spivak, 1987).

The nature of settler colonialism is not only found in the conquest of territories, but also in the social marginalization of othered people groups. Particularly, the United States has found itself in situations of "deliberate attempts to eradicate Native people, and the process of rendering humans into fungible chattel slaves" (Patel, 2016, p. 31). The repercussions of these acts of despotism, coupled with decades of oppression in the Jim Crow south, continue to oppressively limit many minorities today (Alexander, 2010). Over time, minorities, particularly, in the United States have been socially conditioned to feel like they are less than capable, less than qualified, and even less than human (Alexander, 2010; Delpit, 2012). Specifically, in today's society there is an "outgrowth of racial hierarchies that have developed over the nation's history and that have privileged whiteness" (Martin, 2009, p. 330).

In many cases, societal privileges that people experience are often unearned. Those who experience power and privilege in society are often born into circumstances where skin color, socioeconomic status, and beliefs about people groups are not chosen (McIntosh, 1989). In particular, "race may be widely dismissed as a biological classification, [but] dark skin is an easily observed and salient trait that has become a marker in American society, one imbued with meanings about crime, disorder, and violence, stigmatizing entire categories of people" (Sampson, 2012, p. 132). This is particularly true in schools. Many times students are pigeonholed into particular academic tracks based purely on socially constructed potentialities rather than students' interests or personal choices.

Settler colonial ideas routinely become evident through colonization of intellect. When there is no longer territory to conquer or people to physically oppress, there exists opportunities to colonize knowledge (Patel, 2016). Recognizing knowledge as a commodity benefits many that already experience privilege in society, while simultaneously marginalizing those who do not. The resulting oppressive structure is a form of academic apartheid (Irizarry, 2012). 
Tracking students based on ability fuels academic apartheid in mathematics education, as tracking often includes reproduction of social class by creating modern systems of segregation (Kohli, 2015). Injustices like these are evidence of settler colonial ideas, which have permeated schools in neocolonial mutations of an antiquated practice.

\section{Deconstructing Tracking Culture in Mathematics Education}

Throughout time, mathematics has often been seen as an amoral subject (Battey, 2013); however, some have concluded that mathematics, and its accessibility, are next major civil rights issue in the United States (Battey, 2013; Moses \& Cobb, 2001). Throughout the 1980s and 1990s, many minorities began to gain more access to mathematics as a result of progressive, educational initiatives. Oakes and others found that, as universities began placing higher importance on advanced placement courses, many urban schools were able to provide their students with more access to these types of rigorous courses. Nevertheless, many minority students continued to be tracked into lower-level courses, despite access to a wider array of course offerings (Oakes, Joseph, \& Muir, 2003; Werblow et al, 2013). While recognizing this is helpful in beginning to pose alternatives to tracking culture, it cannot singlehandedly solve larger problems of "access to universities, living-wage jobs, and affordable housing" (Battey, 2013, p. 351).

On the surface, functional models of schooling promise equality and choice, but underneath are oppressive systems that promote social stratification (Anyon, 1979, 1981; Van Houtte, Demanet, \& Stevens, 2012). Deeply rooted settler colonial mindsets, coupled with aspects of social Darwinism found in capitalist societies, have provided schools justification to treat minority students differently (Oakes \& Guiton, 1995). Typically, academic tracks in secondary schools are geared to prepare students for pursuits in higher education. On the other hand, vocational tracks most often prepare students for working class jobs (Brunello \& Checchi, 2007). Furthermore, the tracks into which students are sorted are "classified hierarchically in terms of level of abstraction and theorizing, placing technical and vocational tracks at the bottom of this ladder" (Van Houtte et al., 2012, p. 333).

Binaries created through labeling students in systems of tracking send subliminal messages to those who enroll in lower-tracked courses. Students who are placed into academic tracks are often labeled, not only as advanced, but also as good. Binaries, like these, create oppositional views between advanced students and non-advanced students. Additionally, minority students often recognize their overrepresentation in lower-tracked courses. The result is a common belief among many minority students that assumes their white counterparts are simply "smarter" (Irizarry, 2012, p. 299).

The evolution of tracking has cultivated inaccurate beliefs among many minorities that they are not capable of achieving success in more rigorous academic tracks. Schools then "portend a predetermined, pessimistic fate for 
students," based solely on mythically cultivated social beliefs (Irizarry, 2012, p. 300). Over time, these myths begin to become accepted as truths, which have negative impacts on students' learning and school experiences.

In many schools across the United States, tracking has fostered environments where enactments of hidden curricula in schools have created systems of racial segregation (Irizarry, 2012). As Oakes (1990) pointed out, many minority students are not provided the same access to more rigorous courses as their white counterparts. In particular, Love (2002) quoted one teacher as saying:

We thought we were tracking students in or out of higher-level mathematics courses by their ability. Then we looked at the data on student achievement on standardized tests. We learned that African American and Latino students who scored as high as white students were getting tracked out of college-level courses. (p. 3)

Disadvantages like this place some students in positions to where they cannot overcome the social handicaps resulting from being tracked into lowerlevel mathematics courses. "Even if supposedly objective ability groupings appear logical, they are easily confounded with race and social class. Moreover, the differences in opportunities they provide actually limit instruction, rather than fine tune it" (Oakes, 1990, p. vii).

In addition to being unfairly tracked, schools in lower socioeconomic communities, which are generally more racially segregated, have to meet the same standards as other schools, but with access to fewer resources. Werblow, Urick, and Duesbery (2013) found that tracking in academic subjects tends to provide advantages for the already privileged in society and disadvantages students of minority classes. Furthermore, many students sorted into lower academic tracks are often subjected to under qualified teachers. It is often the case that many teachers hired to teach lower-level mathematics courses are alternatively certified or are granted emergency certification in order to quickly fill teaching vacancies (Ingersoll, 2004).

While equal access to resources and highly qualified teachers are major barriers to overcome, minority students in lower academic tracks also have to battle historical social precedents. For instance, the majority of people who enter mathematical fields are traditionally men, many of who happen to be white (Battey, 2013). The lack of diversity in mathematics is also seen in teacher preparation programs and schools throughout the United States (Ladson-Billings, 2005). The absence of cultural diversity in fields like mathematics is, in part, a result of tracking minority students. Minorities and students from lower socioeconomic classes oftentimes have fewer opportunities to learn mathematics due to access of resource and access to qualified mathematics teachers (Lee, 2012; Oakes, 1990: Werblow et al., 2013).

As minority students are often unfairly placed in lower academic tracks because of racial bias and societal precedents, they are often subjected to less rigorous courses. Lower-level courses tend to focus on rote memorization of 
algorithms and rely on traditional teaching techniques that reinforce social stratification (Anyon, 1979, 1981). Furthermore, academic tracking has been found to be a "substantial predictor of student dropout even after accounting for differencing in school academic climate (Werblow et al., 2013, p. 280). Finally, academic tracking not only reinforces social class, but it also creates unhealthy racial boundaries that lead many students to believe that "whiteness and academic success are correlated in a fixed and natural way" (Modica, 2015, p. 87).

\section{Potential Benefits to Tracking}

While the author contends that tracking is primarily a negative social enterprise that benefits the privileged and disadvantages minorities in the US, there are some who contend that tracking is a positive venture (Oakes \& Guiton, 1995). Proponents of tracking tend to believe in more functional models of school, that center on organizing students in order for them to maximize their talents. For some, one benefit of tracking comes from the implementation of standards initiatives such as Common Core State Standards for Mathematics. Matney (2014) found that students in early grades working with (CCSSM) were able to better understand the structure of mathematics and its representations more fluently in problem solving situations. Additionally, Kamin (2016) suggests that CCSSM raises expectations for students and helps schools align their curriculum to be more in sync with college and university expectations.

Parsons (2016) indicated that there may be benefits and little indication of issues with tracking through the middle grades, but found, starting in Algebra 1 , tracking to be more problematic for students. One potential benefit would be to implement policies that allow disadvantaged students the opportunity to transfer schools that would accelerate their coursework (Clotfelter, Ladd, \& Vigdor, 2012). An issue, though, arises in that many disadvantaged students live in rural areas, which makes transferring unfeasible due to complexities around transportation (Hoxby \& Avery, 2013).

\section{Possibilities}

While binary mechanisms, like sorting, are very much ingrained in our consciousness (Capra, 1996), as educators, we must begin to rethink the manner in which we structure our curriculum, especially in mathematics. Research has brought to light many problems associated with tracking students. So, this begs the question of how educational stakeholders can create spaces in schools "where tracking no longer makes sense" (Oakes, 1992, p. 17). In an effort to begin moving mathematics courses that are tracked based upon ability, the National Council of Teachers of Mathematics (NCTM) created an initiative, the Equity Principle, to help support teachers in order to foster supportive classroom communities that can help in this area (Amidon \& Trevathan, 2017; NCTM, 2000). 
Oakes (1992) provided a framework for rethinking schools in order to undermine the socially oppressive DNA of tracking. Oakes recommended rethinking normative behaviors, instituting new political policies, and restructuring school curriculum and instruction. The following possibilities are not one-size-fits-all solutions to problems associated with tracking, nor are these possibilities an over simplification of the issues at hand. Instead, my hope is to build on Oakes's framework to explore transcendent ideas for de-tracking schools in hopes of promoting wider access to mathematics for students of all backgrounds and abilities.

\section{Collaborative Environments}

In reference to the nature of tracking, schools should not be "compelled to continue a practice that reinforces educational inequalities simply because it matches the inequalities of the larger society" (Oakes, 1986, p. 153). Integrating students into oppressive structures is not the solution. The hope is to transform oppressive school structures in order to allow students spaces to no longer be objectified by a system that has disenfranchised them (Freire, 1998, 2000). Because of this, it is crucial to begin creating educational environments where students can share their thoughts, needs, and concerns about what they study. To do this, schools must rethink top-down practices that quash students' and teachers' voices by providing space for democratic communities of practice to emerge.

In many schools, top-down practices have been implemented as onesize-fits-all solutions for controlling others. These practices aim to "produce desirable student behavior" and "maintain procedures, routines, rules, and standards" (Casey, Lozenski, \& McManimon, 2013). A potential problem with this is that students' voices are homogenized. Rarely, if at all, are students' interests taken into consideration in the current model of mathematics curriculum.

In order to rethink the hierarchical nature of mathematics curricula, communities of practice must begin to work together to rethink school environments. These collaborations should include students, teachers, administrators and other stakeholders. When in practice, collaborative communities form "a strong bond of people who are committed to working together toward goals and purposes that they share with each other" (Sergiovanni, 2004, p. 20). Taking into consideration multiple perspectives allows schools to begin catering to students' interests and their intellectual curiosities. Embracing the heterogeneity of student populations is one way to begin dismantling tracking in schools (Burris \& Garrity, 2008).

\section{Curriculum Driven by Student Interest}

Traditional disciplines, like mathematics, tend to be sequential, hierarchical, and impermeable. One alternative is for schools to open their mathematics curricula to become more interdisciplinary, providing access for 
more students (Bernstein, 1977). Relying on innovative instructional practices alone is "not enough to address the damage to student identity that results from years of participation in tracked systems" (Modica, 2015, p. 88). In order to begin changing the current hierarchical system, schools must begin building curricula driven by students' interests that also connects to their lived experiences (Delpit, 2012; Dewey, 1950; Noddings, 2013a).

Oftentimes, we associate mathematically driven disciplines as being more rigorous than those outside of the hard sciences. It then follows that those who excel in mathematics are deemed more intelligent than those who do not. Ernest (1991) noted:

There is a widespread assumption . . . that there is a fixed linear hierarchy of mathematical ability from the least able to the most able (or mathematically gifted), every child can be assigned a position in this hierarchy, and few shift their position during the years of schooling. One important consequence of these stereotyped perceptions and expectations of pupils is the adoption of limited goals for the mathematical education of lower attaining pupils. (p. 244)

Tracking students in mathematics tends to play into these assumptions, and leads many to believe they are true.

While traditional mathematical content is intriguing to some, it is often the case that many students do not find interest in learning pure mathematics. Additionally, many students struggle with mathematics at one point or another in their schooling, and as a result, struggling students are often tracked into lower-level courses. However, if students begin to take an interest in mathematics (or any subject for that matter), they remain stuck in the track in which they were initially placed. In order to move out of lower tracks, students must take on the monumental task of concurrently enrolling in multiple courses during their secondary schooling, otherwise they remain trapped.

Taking into consideration the limitations of being tracked into less rigorous courses, many students are sometimes hesitant to pursue their interests due to negative stigma associated with vocational, home, and non-scholarly pursuits (Noddings, 2013a). "By making technical/vocational education a positive choice, the intake of students could change, as students' curriculum choices would be based on interest rather than on failure, resulting in a more heterogeneous student composition in the different tracks in terms of cognitive capacity and social background" (Van Houtte et al., 2012, p. 347). Incorporating more positive views of vocational and technical learning allows mathematics to become more accessible to students of all abilities.

In order to achieve enacted curricula, void of negative stigma and driven by students' interests, highly qualified teachers are essential to creating explorative courses that rely heavily on cooperative learning. To achieve such a lofty goal, Freire's (2000) notion of teachers and students working as coinvestigators must have room to exist. While teachers need to fully understand 
their content, they must also be prepared to facilitate classrooms where students can investigate mathematical topics based on their intellectual curiosities.

The notion of relying on intellectual curiosities harkens back to Whitehead's (1967) rhythm of education. Initially, students may take an interest in a particular aspect of the subject matter in which they are studying. Strict adherence to curricula oftentimes prevents students from exploring their "romances" within academic disciplines. Instead, the manner in which mathematical curriculum is structured ought to give students opportunities to explore these curiosities. Later, students can more fully flesh out the precision and generalization required to more fully understanding the technical aspects associated with the topic.

An interesting notion to consider, which dovetails nicely with Whitehead's rhythm of education, is the idea of renewing the spirit of the liberal arts (Noddings, 2013a, 2013b). While the traditional liberal arts may be rooted in traditionally academic forms of education (Schiro, 2013), the spirit of the liberal arts is grounded in individuals' intellectual and epistemological curiosities. Providing students space to explore aspects of mathematics they find interesting, even within conventional mathematics education curricula, allows students to pursue their interests while also learning more in-depth components of the subject matter.

In a democratic society like the United States, education should mirror the democratic ideals of choice and individual voice. In systems like tracking, students are usually not given choices in deciding the track in which they are placed. As schools rethink this, it is imperative to remember that "choice is a basic concept in democracy" and students should be given choice in their curricular pursuits (Noddings, 2013a, p. 66).

\section{Integrating Multiple Perspectives in Mathematics Curriculum}

If schools are willing to begin rethinking their current curricular models of mathematics, there becomes room for multiple perspectives to exist in a traditionally Eurocentric discipline. Classrooms formed around students' interests, rather than homogeneous ability groupings, allow for more heterogeneity in classrooms. The diversity in student's interests can allow students opportunities to explore areas of mathematics not traditionally taught in schools.

While some students may be more inclined to think and process information in a more logical-mathematical manner (Gardner, 2006), students of all backgrounds are capable of learning mathematics. "Just as race is a sociopolitical construction, so are standards for who is judged to be mathematically literate" (Martin, 2009, p. 318). When students are placed into lower academic tracks, they are often seen to be less mathematically capable than their higher-tracked counterparts. For these reasons, we must begin rethinking how we structure mathematics curriculum in secondary schools. The 
following ideas build upon essential democratic ideals and beckon stakeholders to begin designing curriculum outside of the traditional norm.

Rethinking mathematical labels. Mathematics curricula in the United States predominantly follow a sequence of courses that builds hierarchically over time. As students climb the proverbial mathematical ladder, each course provides a foundation for the next in the sequence. As noted, there exist problems with hierarchical curricula. In particular, top-down strata are often created which give students in higher tracks more "cultural capital" (Bourdieu, 1986) than their lower-tracked peers. Students in more advanced courses generally have access to better resources, while lower-tracked students tend to have less resources available to them. In order to combat social stratifications, some schools have moved to labeling courses differently. For example, rather than offering traditional, topic-centered courses, schools can design courses around students' interests, which also fit within their zones of proximal development. As most students are in secondary school for four years, one idea is to begin by taking Math 1 and progress sequentially to Math 4 . In this case, a potential Math 1 course may include issues around better understanding the foundations of functions and geometric reasoning. Rather than segregating high school subject matter, courses in this suggestion blur the lines between algebra, geometry, and calculus in order to allow student opportunities to explore mathematics in a more holistic manner.

When removing names of mathematics courses, the stigma associated the class labels becomes less important. In this situation, there is no longer a necessity for labels such as honors, regular, or advanced. Also keeping in mind that Math 1 is not the same as Algebra 1, students are able to explore nontraditional fields in mathematics, which can help cultivate intellectual curiosity. By moving away from traditional labels, students are no longer relegated to learning atomized sets of standards found in topic-centered courses. Instead, the curriculum is opened for students to explore areas of mathematics outside of the norm and which coincide with their interests.

Historicizing mathematics. Placing mathematics in the context of history is another possibility for rethinking mathematics curriculum. Rather than relying on traditional sequences of secondary mathematics that begin with Algebra 1 and culminate with higher-tracked students enrolling in calculus or statistics, teaching mathematics through the context of history is one way to eliminate this hierarchy. While still linear in nature, students are simultaneously afforded opportunities to learn concepts found in algebra, geometry, statistics, and calculus. Rather than teaching these subjects as separate courses, students are able to adopt the role mathematicians play as they uncover mathematical discoveries found throughout history. For instance, imagine a course where students work through historical texts like Euclid's Elements. In a scenario like this, students learn fundamental axioms associated with high school geometry 
curriculum, while also working through interesting dilemmas faced by early geometers.

When historicizing mathematics, students are able to make personal connections with the names associated with various theorems, problems, and laws. This idea also lends itself to conversations about the Euro-centricity of mathematics. When working through historically rooted mathematical topics, many may discover how Eurocentric the curriculum actually is. As students' interests drive groups to investigate mathematical discoveries in other cultures, there may be space to open the curriculum further to incorporate topics found in ethnomathematics.

As with most historical accounts, there is usually the question of whose history will be told, and from whose perspective will it be told. One way to combat monolithic voices from dominating the historical narrative of mathematics is to intentionally allow students and teachers opportunities to explore different mathematical perspectives. To do this, it makes sense to include topics found in fields like ethnomathematics. Ethnomathematics is essentially mathematics that is "practiced among identifiable cultural groups, such as national-tribal societies, labor groups, children of a certain age bracket, professional classes, and so on" (D'Ambrosio, 1985, p. 45). While any form of mathematics produced can technically be deemed "ethno-mathematical," a primary goal of ethnomathematics is to provide alternatives to Eurocentric mathematical thinking (Borba, 1990). As Battey (2013) noted, people of color are often underrepresented in mathematics; therefore, by historicizing mathematics and integrating ethnomathematical ideas into schools' curricula, students are able to gain a better understanding of the cultural diversity within the discipline.

Teaching mathematics for social justice. Just as incorporating diverse perspectives into mathematics is imperative to rethinking mathematics curriculum, so is presenting curriculum that is culturally relevant. Building upon the notion of providing choice in students' schooling, teaching mathematics for social justice gives students opportunities to problematize challenges present in the world today (McGee \& Hostetler, 2014). Implementing culturally relevant pedagogies offers alternatives to traditional curricular models while also providing opportunities to contextualize learning and "develop a less mystified view of mathematics" (Brelias, 2015, p. 9). Teaching mathematics for social justice requires teachers to be up-to-date on current issues facing their students' communities. This form of teaching mathematics is difficult to retrofit into the current hierarchical structure of mathematical curriculum. Restructuring curriculum around students' needs allows courses to form around social issues. For instance, mathematics courses in schools can be aligned to issues of gentrification, immigration, race, and other topics pertinent to local communities. 
Tailoring curriculum around students' interests in social issues meshes well with building curricula based on intellectual curiosities. This also gives students relevant opportunities for making sense of the world around them. In teaching mathematics for social justice, the traditional lines around academic disciplines begin to blur. Rethinking curriculum, in this sense, allows mathematics to potentially branch into other areas of study. In scenarios like these, students' learning is not compartmentalized into rigid, academic disciplines. Rather, traditional curricula become blended and more diverse (Bernstein, 1977). As curriculum is restructured to work within frameworks of providing students democratic choices, it is no longer necessary track students based on their ability. The results include students guiding their curricular endeavors and learning how to advocate for their personal learning experiences.

\section{Conclusion}

Theoretical literature suggests that tracking is a manifestation of functional, capitalist models for education, which strive to fill economic voids in society. As a result, traditional academic tracks in mathematics create unhealthy stratifications in schools. While student choice should be considered if tracking is to exist, enrollment decisions are often based on socioeconomic status or race instead of one's mathematical ability or interest. These divisions, both intentionally and unintentionally created, serve to reproduce social class and solidify hierarchical ways of thinking.

In order to combat the societal issues associated with tracking, educational stakeholders must begin rethinking how schools are structured and how content is taught. The author argues that environments created in schools should be collaborative and democratic in nature. Healthy school environments serve as foundations for implementing curricula based on students' interests. This helps eliminate negative stigma surrounding choices for vocational schooling and other non-academic work.

Finally, to de-track our schools, schools must rethink how mathematics curricula are enacted. The author suggests schools begin thinking through possibilities that encourage collaborative work, investigation, and cultural relevance. By rethinking mathematical labels, teaching mathematics through historical contexts, and basing curricula around issues of social justice, schools are able to connect learning to students' lives. If we truly believe in democracy and valuing students' perspectives, rethinking traditional mathematical curricula is necessary for helping students find balance between explorations of "cosmic wonder" within the discipline and making relevant connections to their lives (Noddings, 2013a, p. 59). This allows for students to engage in more meaningful work that builds on intellectual curiosities rather than atomized sets of disconnected standards. 


\section{References}

Anyon, J. (1979). Social class and the hidden curriculum of work. Journal of Education, 162(1), 67-92.

Anyon, J. (1981). Social class and school knowledge. Curriculum Inquiry, $11(1), 3-42$.

Alexander, M. (2010). The new Jim Crow: Mass incarceration in the age of colorblindness. New York, NY: New Press.

Barquet, N. (1992). Beyond tracking. Equity Coalition for Race, Gender, and National Origin, 3(1), 3-6.

Battey, D. (2013). Access to mathematics: "A possessive investment in whiteness". Curriculum Inquiry, 43(3), 332-359.

Bobbitt, F. (1924). The new technique of curriculum-making. The Elementary School Journal, 25(1), 45-54.

Borba, M. (1990). Ethnomathematics and education. For the Learning of Mathematics, 10(1), 39-43.

Bourdieu, P. (1986). The forms of capital. Cultural theory: An anthology, 8193.

Brelias, A. (2015). Mathematics for what? High school students reflect on mathematics as a tool for social inquiry. Democracy \& Education, 23(1), 1-11.

Brunello, G., \& Checchi, D. (2006). Does school tracking affect equality of opportunity? Economic Policy, 22(52), 782-861.

Burris, C., \& Garrity, D. (2008). Detracking for excellence and equity. Alexandria, VA: Association for Supervision and Curriculum Development.

Capra, F. (1996). The web of life: A new scientific understanding of living systems. New York, NY: Anchor.

Casey, Z., Lozenski, B., \& McManimon, S. (2013). From neoliberal policy to neoliberal pedagogy: Racializing and historicizing classroom management. Journal of Pedagogy, 4(1), 36-58.

Clotfelter, C. T., Ladd, H. F., \& Vigdor, J. L. (2012). Algebra for 8th graders: Evidence on its effects from 10 North Carolina districts. NBER Working Paper No. 18649.

D'Ambrosio, U. (1985). Ethnomathematics and its place in the history and pedagogy of mathematics. For the Learning of Mathematics, 5(1), 44-48.

Delpit, L. (2012). Multiplication is for white people. New York, NY: New Press.

Dewey, J. (1950). The child and the curriculum (25th ed.). Chicago, IL: The University of Chicago Press.

Ellsworth, E. (1992). Teaching to support unassimilated difference. Radical Teacher, 42, 4-9.

Ernest, P. (1991). The philosophy of mathematics education. London, UK: Routledge Falmer.

Freire, P. (1998). Pedagogy of freedom: Ethics, democracy, and civic courage. 
Lanham, MD: Rowman \& Littlefield Publishers.

Freire, P. (2000). Pedagogy of the oppressed. New York, NY: Continuum.

Gardner, H. (2006). Multiple intelligences: New horizons. New York, NY: Basic Books.

Hixson, W. (2013). American settler colonialism: A history. New York, NY: Palgrave McMillan.

Hoxie, F. (2008). Retrieving the red continent: Settler colonialism and the history of American Indians in the US. Ethnic and Racial Studies. 31(6), 11531167.

Houser, N., Krutka, D., Province Roberts, R., Pennington, K., \& Faili Coerver, N. (2017). Navigating the reform-accountability culture in Oklahoma social studies. Theory \& Research in Social Education, 45(1), 7-42.

Hoxby, C., \& Avery, C. (2013). The missing "one-offs": The hidden supply of high-achieving, low income students. Brookings Papers on Economic Activity.

Ingersoll, R. (2004). Why some schools have more underqualified teachers than others. Bookings Papers on Education Policy, 7, 45-88.

Irizarry, J. (2012). Los caminos: Latino/a youth forging pathways in pursuit of higher education. Journal of Hispanic Higher Education, 11(3), 291-309.

Kamin, D. (2016). The common core state standards for mathematics and college readiness. The Mathematics Educator, 25, 52-70.

Kilpatrick, J. (2014). Mathematics education in the United States and Canada. In A. Karp \& G. Schubring (Eds.), Handbook on the History of Mathematics Education (pp. 323-334). New York, NY: Springer.

Kim, J., \& Sunderman, G. (2004). Large mandates and limited resources: State response to the No Child Left Behind Act and implications for accountability. Cambridge, MA: The Civil Rights Project at Harvard.

Kohli, S. (2015). Modern-day segregation in public schools. Retrieved from https://www.theatlantic.com/education/archive/2014/11/modern-daysegregation-in-public-schools/382846/

Ladson-Billings, G. (2005). Is the team all right? Diversity and teacher education. Journal of Teacher Education, 56(3), 229-234.

Lee, J. (2007). The testing gap: Scientific trials of test-driven school accountability systems for excellence and equity. Charlotte, NC: Information Age.

Lee, J. (2012). Educational equity and adequacy for disadvantaged minority students: School and teacher resource gaps toward national mathematics proficiency standard. The Journal of Educational Research, 105(65), 6475.

Love, N. (2002). Using data/getting results: A practical guide for school improvement in mathematics and science. Norwood, MA: ChristopherGordon Publishers.

Martin, D. (2009). Researching race in mathematics education. Teachers College Record, 111(2), 295-338. 
Matney, G. (2014). Early mathematics fluency with CCSSM. Teaching Children Mathematics, 21(1), 27-35.

McGee, E., \& Hostetler, A. (2014). Historicizing mathematics and mathematizing social studies for social justice: A call for integration. Equity \& Excellence in Education, (47)2, 208-229.

McIntosh, P. (1989). White privilege: Unpacking the invisible knapsack. Peace \& Freedom, 10-12.

Modica, M. (2015). "My skin color stops me from leading": Tracking, identity, and student dynamics in a racially mixed school. International Journal of Multicultural Education, 17(3), 76-90.

Moses, R., \& Cobb, C. (2001). Radical equations: Civil rights from Mississippi to the Algebra Project. Boston, MA: Beacon.

National Council of Teachers of Mathematics. (2000). Principles and standards for school mathematics. Reston, VA: Author.

Noddings, N. (2013a). Education and democracy in the 21st century. New York, NY: Teachers College Press.

Noddings, N. (2013b). Renewing the spirit of the liberal arts. Journal of General Education, 62 (2-3), 77-83.

Oakes, J. (1986). Keeping track, part 2: Curriculum inequality and school reform. The Phi Delta Kappan, 68(2), 148-154.

Oakes, J. (1990). Multiplying inequalities: The effects of race, social class, and ability grouping on access to sciences and mathematics education. Santa Monica, CA: RAND.

Oakes, J. (1992). Can tracking research inform practice? Technical, normative, and political considerations. Educational Researcher, 21(4), 12-21.

Oakes, J. (2005). Keeping track: How schools structure inequality (2nd ed.). New Haven, CT: Yale University Press.

Oakes, J., \& Guiton, G. (1995). Matchmaking: The dynamics of high school tracking decisions. American Educational Research Journal, 32(1), 333.

Oakes, J., Joseph, R., \& Muir, K. (2003). Access and achievement in mathematics and science: Inequalities that endure and change. In J. Banks \& C. Banks (Eds.), Handbook of research in multicultural education (2nd ed.). San Francisco, CA: Jossey-Bass.

Parsons, E. (2016). Does attending a low-achieving school affect highperforming student outcomes? Teachers College Record, 118(8), 1-36.

Patel, L. (2016). Decolonizing educational research: From ownership to answerability. New York, NY: Routledge.

Powell, J. \& Menendian, S. (2016). The problem of othering: Towards inclusiveness and belonging. Othering \& Belonging, 1, 14-39.

Raudenbush, S., Fotiu, R., \& Cheong, Y. (1998). Inequality of access to educational resources: A national report card for eighth-grade math. Educational Evaluation and Policy Analysis, 20(4), 253-267. 
Rippa, S. A. (1984). Education in a free society: An American history (5th ed.). New York, NY: Longman.

Said, E. (1978). Orientalism. New York, NY: Pantheon.

Sampson, R. (2012). Great American city: Chicago and the enduring neighborhood effect. Chicago, IL: University of Chicago Press.

Schiro, M. (2013). Curriculum theory: Conflicting visions and enduring concerns (2nd ed.). Thousand Oaks, CA: Sage.

Sergiovanni, T. (2004). Balance individual autonomy and collaboration to center on students. The Education Digest: Essential Readings Condensed for Quick Review, 70(3), 17-22.

Spivak, G. (1987). In other worlds: Essays in cultural politics. York, UK: Methuen.

Teitelbaum, M. (2014). Falling behind?: Boom, bust, and the global race for scientific talent. Princeton, NJ: Princeton University Press.

Van Houtte, M., Demanet, J., \& Stevens, P. (2012). Curriculum tracking and teacher evaluations of individual students: selection, adjustment, or labeling? Social Psychology of Education, 16(2), 329-352.

Werblow, J., Urick, A., \& Duesbery, L. (2013). On the wrong track: How tracking is associated with dropping out of high school. Equity \& Excellence in Education, (46)2, 270-284.

Wheelock, A. (1992). Crossing the tracks: How "untracking can save America's schools. New York, NY: The New Press.

Whitehead, A. (1967). The aims of education, and other essays. New York, NY: Free Press.

Wolf, P. (1999). Settler colonialism and the transformation of anthropology: The politics and poetics of an ethnographic event. New York, NY: Cassell.

\section{Author:}

Cacey L. Wells

University of Oklahoma, USA

cwells@ou.edu 